\title{
28 Research Soure \\ Gpr Application for the Characterization of Sinkholes in Teresina, Brazil
}

\author{
Alexandre Lisboa Lago ( $\nabla$ alexandre.lago@cprm.gov.br ) \\ Geological Survey of Brazil https://orcid.org/0000-0001-5965-5907 \\ Welitom Rodrigues Borges \\ Universidade de Brasilia \\ José Sidney Barros \\ Geological Survey of Brazil \\ Elizângela de Sousa Amaral \\ Geological Survey of Brazil
}

\section{Research Article}

Keywords: GPR, Geophysics, Subsidence, Collapse, Sinkholes, Teresina

Posted Date: August 4th, 2021

DOI: https://doi.org/10.21203/rs.3.rs-611044/v1

License: (c) (1) This work is licensed under a Creative Commons Attribution 4.0 International License.

Read Full License

Version of Record: A version of this preprint was published at Environmental Earth Sciences on February 1st, 2022. See the published version at https://doi.org/10.1007/s12665-022-10265-4. 


\section{Abstract}

The town of Teresina, in the state of Piauí, Brazil, presents a history of land sinking processes. Two sinking events deserve to be highlighted, the first occurred in 1999 at Simplício Mendes street and the other occurred on July 31, 2008, at Francisco Mendes street. In order to identify possible shallow caves and associated structures, the Geological Survey of Brazil/CPRM developed a Ground Penetrating Radar (GPR) study to verify the occurrence of reflection patterns characteristic of these dissolution structures. In the field, the team conducted GPR sections along streets with a history of collapse. The GPR results obtained with shielded antennas of $200 \mathrm{MHz}$ allowed the identification of old areas of collapse of the terrain, to a maximum depth of 3 meters. In addition, the results obtained by this study show the potential of applying the GPR method in the characterization of the subsoil of paved streets, making it possible to identify various layers: asphalt, actual pavement, subgrade pavement, soil, saprolite, and mixed material. The high clay content of the subsoil does not allow the GPR to investigate further depths in the research area. The interpretation of aeromagnetometric data shows that the occurrence of sinkholes is associated with magnetic lineaments mainly in the NW-SE direction and enhances the understanding of the structural framework of the study area.

\section{Highlights}

- Characterization of reflection patterns

- GPR as a tool for the practical recognition of sinkholes

- Agility to identify shallow caves and associated structures with GPR

\section{Introduction}

In Brazil, the verticalization of urban spaces due to higher living standards and the construction of tall buildings in urban areas, in addition to the progressive growth of land use by mining, civil engineering, and agriculture activities, have generated impacts on the physical environment, as in the case of karst terrains. In this context, the significant areas of karst terrains in several Brazilian cities (Cajamar-SP, Lapão-BA, Teresina-PI, Curvelo-MG, Bocaiúva do Sul-PR, Sete Lagoas-MG, Almirante Tamandaré-PR e Colombo-PR), means that there are potential geological risks for phenomena that generate subsidence and collapse of cavities under these cities. According to Vestena (2002), the subsidence which has occurred in the cities of Cajamar-SP, Sete Lagoas-MG, Almirante Tamandaré-PR, and Colombo-PR are associated with karst terrains, where the lowering of the water table contributed to the process of soil collapse / subsidence.

In light of this, the geological risk associated with karst areas is worrying since in this type of geological environment, soil subsidence and cavity collapse can become a social and economic threat, which is intensified by the urbanization of these cities (Vestana 2002; Waltham et al. 2005; Gutiérrez et al. 2015). 
Karst terrains are formed by the surface and subsurface dissolution of carbonate and evaporite rocks, which are commonly characterized by challenging geotechnical conditions (Rodriguez et al. 2014). However, some authors call attention to less soluble rocks that can develop karst settings, such as sandstones and quartzites (Martini 2000; Frumkin 2013). It's worth noting that in karst settings, problems related to subsidence and collapse can be caused by natural phenomenon or by anthropic activity. Subsidence sinkholes are the main risk in karst terrains (Waltham et al. 2005; Gutiérrez 2010; Rodrigues et al. 2014).

Considering the heterogeneous character and susceptibility of karst terrains to subsidence and collapse, geophysical studies and investigations using multiple approaches are extremely important for providing information on the subsurface, enabling the identification and characterization of features associated with sinkholes (Milanovic 2000; Thierry et al. 2005; Ezersky et al. 2006; Ezersky 2008; Argentieri et al. 2015). According to Lelièvre et al. (2009), due to the ambiguity of the results obtained by a single geophysical method, the integrated application of various geophysical methods in the study of an area is necessary in order to provide more reliable information and results (Dourado et al. 2001; Kruse et al. 2006; Lago et al. 2006; Lago et al. 2008; Nouioua et al. 2012; Sevil et al. 2017; Pazzi et al. 2018; Hussain et al. 2020).

The effectiveness of a geophysical survey is conditioned by the existence of contrasts between the measured physical property values. Therefore, considering changes in the physical properties of materials caused by the processes of dissolution, erosion, and subsidence involved in the development of sinkholes, geophysical methods are an excellent tool for indirect investigation (Hoover 2003). In general, the use of geophysical surveys in the characterization of karst terrains consists of the detection and mapping of the extension of sinkholes as well as information about the depth of the water table, direction of the underground flow, and depth of the karst rocks (Chalikakis et al. 2011).

Among the geophysical methods, the Electrical Resistivity (ER) method is widely used in several fields of study such as mining (Arifin et al. 2019), engineering geology (Rucker et al. 2011), hydrogeology (Revil et al. 2012), environmental studies (De Lima et al. 1995; Chambers et al. 2006), agricultural studies (Michot et al. 2003) and cavity studies (Smith 1986; Martinez-Lopez et al. 2013; Hussain et al. 2020). However, despite the countless geophysical investigations carried out on karst terrains worldwide, (mainly for mapping cavities) the Ground Penetrating Radar (GPR) method has proven to be the most efficient geophysical method for identifying geometric karst features in urban environments. As such, over the past couple of decades the use of the GPR method has increased and many improvements have been successfully implemented (McMechan et al. 1998; Zisman et al. 2005; Kruse et al. 2006; Rodriguez et al. 2014; Sevil et al. 2017; Hussain et al. 2020). In light of the results of these authors, the GPR method has shown effectiveness in mapping urban areas affected by subsidence and collapse in karst environments and has contributed to a better assessment of the risks associated with this geological environment.

The physical principle and data acquisition of GPR methodology are similar to the seismic reflection and the sonar techniques, except that the GPR is based on the reflection of electromagnetic waves (Casas et 
al. 2000). According to Annan (2002), this method stands out for shallow investigations, due to its high resolution and the acquisition of a large volume of data in a short period of time. The depth of investigation is a limitation of the GPR method and can be influenced by the following factors: geometric scattering, attenuation by the terrain, and partition of energy at the interfaces, which are all related to the loss of energy during the propagation of the electromagnetic wave (Bradford 2007). The depth of investigation and the resolution of the GPR vary according to the frequency of the antenna. The higher the frequency, the higher the vertical resolution and the lower the depth of investigation, and vice versa.

Kruse et al. (2006) in the publication "Sinkhole Structure Imaging in Covered Karst Terrain", show that GPR and resistivity techniques have been widely used to map the locations of sinkholes in covered karst terrain. The authors acquired GPR and resistivity data in the west-central region of Florida, USA. According to the authors, the GPR method provided detailed information on the geometry of sinkholes developed within covered karst terrain. Rodriguez et al. (2014) applied the GPR method in two studies of sinkholes developed in the mantled evaporite karst of Zaragoza city in Spain, with the purpose of evaluating the potential of GPR for the characterization of sinkholes in covered karst. The authors concluded that GPR was an effective technique for the identification and characterization of shallow collapse and sagging subsidence structures in covered karst areas. GPR allowed for the reliable mapping of the limits of the sinkholes (characterizing their internal geometries), their inferred subsidence mechanisms, and estimates of their morphometric parameters. Continuing geophysical studies in the city of Zaragoza, Spain, Sevil et al. (2017) analyzed and compared the data acquired by the GPR and Electrical Resistivity Tomography (ERT) methods. In addition, the authors suggested the use of shielded antennas as the best option for surveys with the GPR method in urban areas.

Within this context, the study at hand consists of the imaging of subsidence areas by the GPR method in the city of Teresina-PI. According to geotechnical studies, $9 \%$ of the city of Teresina-PI has a high chance of a collapse and $45 \%$ of the city has a medium chance of collapse (Aquino 2020). The collapse and subsidence of soil and rock are the result of the evolution of karst reliefs, the degree of dissolution of the rock, and the evolution of cavities in the subsoil. The city developed mainly on sedimentary rocks included in the Pedra de Fogo Formation (Permian). The rocks of this formation are susceptible to dissolution processes, as seen in the processes of subsidence and / or collapse that have occurred widely in the central region of the city.

The Geological Survey of Brazil (CPRM), as part of the Emergency Action of Sectorization of Areas with Risks of Subsidence in Karst Environments, carried out a geophysical study with GPR for the evaluation and characterization of the sinkhole events that occurred in the city of Teresina-PI. Taking into consideration the lack of published articles of this nature in the technical scientific literature, this article is innovative in advancing the knowledge of this particular case study in Brazil. The article presents a model which includes a set of geological and pedological factors that caused the sinkholes and collapses in the city of Teresina-PI, as well as integrating results obtained through the GPR method with data from regional aeromagnetometric studies. 


\section{SITE DESCRIPTION}

The capital city of Teresina, in the State of Piauí, is located on the banks of the Parnaíba River and covers an area of $1,756 \mathrm{~km}^{2}$. The central area of the city, located between the Parnaíba and Poti rivers, has a highly fragile subsoil and subsequently a history of sinkholes, which have been triggered by the drilling of tubular wells, fluctuations in the water table, and leaks in the sewage and hydraulic networks (Pimentel 2008; Fig. 1). Two sinking events deserve to be highlighted: the first occurred in 1999 at Simplício Mendes Street and was related to the drilling of a cavity in the subsoil that caused the collapse of both homes and the street itself (Fig. 2a). The second occurred on July 31, 2008, at Francisco Mendes street (Fig. 2b).

Teresina-PI was created in 1852 as a planned city with a geometric shape in the form of a chessboard, and was the first planned city in Brazil (Viana 2007). From 1970 onwards a process of verticalization began, which accelerated strongly in the late 1980s with the construction of many high-rise buildings (Façanha 1998, 2003). However, it is not possible to say whether the geotechnical weaknesses characteristic of the soils and rocks of Teresina were well known to the municipal technical entities and particularly to the construction companies operating in the municipality.

On Francisco Mendes street, the soil (silty sand) presented mechanical and microstructural behavior typical of collapsible soil as shown in the geotechnical study made by Aquino (2020). From the author's perspective, there was no single cause for the sinking of this street, rather there were a combination of factors which contributed to the triggering of the accident, both of a pedological and geological nature. The collapse events in the city were related to natural factors aggravated by anthropic action including: leakage from a pipe, infiltration of rainwater, leakage in the hydraulic network, fluctuations in the water table, and tectonic events (leading to fractures).

Fractures are associated with the formation of dolines or small cavities in the subsoil, leading to the possibility of free circulation of water and gases. The limestone intercalation with other rocks, typical of the Parnaíba sedimentary basin (Castro et al. 2016), increases the dissolution power of the water on the rocks.

The city of Teresina-PI is developed mainly on sedimentary rocks included in the Pedra de Fogo Formation, which consists of alternating horizons of medium to fine sandstones with cross-stratification and discontinuous silexite and carbonate horizons. At the base of the Pedra de Fogo formation, there are soft sandstones (fine kaolinitic) that are very friable. These lithologies are overlapping the sediments of the Piauí Formation.

The sediments of the Pedra de Fogo Formation are susceptible to dissolution processes that occur at carbonate levels and which may be a condition of the collapse processes that are occurring widely in the central region of the city. The collapses in Teresina-PI are related to natural factors aggravated by anthropic action (rainwater infiltration, leakage in the hydraulic network, water table fluctuations and 
geological faults), and considering these factors, a Geological Model was proposed in this work for the city (Fig. 3).

\section{Methodology}

The methodology used in the work consisted of analyzing regional information to obtain information on the main shear structures present in the area. Subsequently, there were investigations using the GPR method to identify the reflection patterns related to the old dissolution structures. After this stage, GPR sections were carried out along city streets with high density of buildings.

Geophysical regional investigations

The application of aerogeophysical data for use in geological mapping is an important tool that provides for understanding of the distribution of geological units and structural features, through various products generated by digital aerogeophysical data processing techniques (Mekkawi et al. 2017). The interpretation of aerogeophysical products for use in geological cartography is widely reported in the technical-scientific literature, with Boyd (1976) being one of the first to use this methodology. The study of the structural framework of the area was carried out by an integrated macro-structural analysis of aeromagnetometry and satellite images (Shuttle Radar Topography Mission - SRTM), enabling the interpretation of lineaments in the structural fabric of the area. These occur in several directions and highlight faults / folds related to ruptile deformations in the NE-SW directions and ductile-ruptile deformations mainly in the NNW-SSE and NW-SE directions.

The aeromagnetometric data used in this work were acquired by the Maranhão Basin Aeromagnetometric Project - West Block (Consórcio ENCAL / LASA / PROSPEC 1988), totaling 57,951 km of profiles in an area of $143,200 \mathrm{~km}^{2}$. The acquisition parameters of this aerogeophysical survey were: spacing between flight lines of $3 \mathrm{~km}$, spacing between tie-lines of $18 \mathrm{~km}$, flight line N-S direction, tie-line E-W direction, flight height of $500 \mathrm{~m}$, airplane average speed of $200 \mathrm{~km} / \mathrm{h}$, and sampling interval of $100 \mathrm{~m}$.

After processing the aeromagnetometric data, four geophysical images were generated: Anomalous Magnetic Field, Anomalous Magnetic Field Reduced to the Pole, First Vertical Derivative of the Anomalous Magnetic Field and First Vertical Derivative of the Anomalous Magnetic Field Reduced to the Pole (Fig. 4). These support the interpretation of magnetic lineaments in the municipality (generally reflecting the deepest structures), as well as making possible an understanding of the city's structural fabric. The magnetic lineaments, linear or curvilinear, are principally in the NW-SE and NE-SW directions. The sinkholes that occurred in the city of Teresina-PI are mainly associated with the NW-SE trend, as observed in the geophysical images.

After the analysis of the aerial images (SRTM), interpretation of magnetic anomalies and with the available geological information, a geological map was prepared for the city of Teresina to verify the 
correlation of the geological lineaments with the sinkholes (Fig. 5). As observed in the Geological Map of the municipality, the Pedra de Fogo and Piauí formations cover $90 \%$ of the total area of the municipality, and the Motuca and Corda formations cover a smaller portion.

The lithologies related to the Piauí Formation consist of gray to whitish sandstones, topographically lower, from fine to medium and well selected, possibly conglomeratic, interspersed with red shale and clear limestone, outcropping to the north of the city close to the Parnaíba river. In its lower portion there are thick banks of fine to medium sandstone, not very clayey, pinkish reddish, sub-rounded, while in the upper part shales and claystones with dolomite intercalations predominate.

\section{GPR investigations}

The GPR method is commonly used in geotechnical studies that involve the identification of underground cavities because of its speed in obtaining data and results (Anchuela et al. 2009; Anchuela et al. 2014). In this work, to calibrate the acquisition of GPR data in the metropolitan area of Teresina, 2D investigations were carried out in areas with a history of cave collapse. The two events described in this work refer to the sinking of land caused by the drilling of caves, and consequently their collapse. GPR data were acquired with the shielded $200 \mathrm{MHz}$ antennas (Fig. 6).

The data were acquired by moving the GPR through the common offset technique. The acquisition parameters were:

- $1700 \mathrm{MHz}$ and $3400 \mathrm{MHz}$ sampling frequency, resulting in temporal windows of $300 \mathrm{~ns}$ and $150 \mathrm{~ns}$, respectively;

- For the 300 ns and 150 ns windows, 1024 samples per trace were used, providing a temporal interval of $0.2929 \mathrm{~ns}$ and $0.1464 \mathrm{~ns}$ respectively;

- The sampling interval between the traces was $2.5 \mathrm{~cm}$ and $5 \mathrm{~cm}$. The shoots and trace records were registered continuously with the use of a calibrated wheel.

The data was processed with the ReflexW software, version 7.0 (Sandmeier 2012). The 2D data processing routine consisted of:

- IMPORT - file format conversion (*.dzt - output from SIR3000 equipment, to *.dat format - ReflexW file);

- SET TIME ZERO - adjustment of the first arrival of the electromagnetic wave;

- ENERGY DECAY (gain) - applied to recover the attenuated amplitude of the electromagnetic signal during signal propagation in the medium;

- BACKGROUND REMOVAL (2D filter) - removal of coherent noise related to the reverberation of the electromagnetic wave within the antenna shield and external noises;

- BANDPASS (1D filter) - elimination of electronic and static noise inherent to the system;

- LINEAR GAIN - applied to highlight the amplitudes lost with spherical scattering; 
- SPECTRAL WHITENING - applied for flattening the frequency spectra to enhance vertical resolution and reduce the influence of periodic artifacts;

- FK FILTER - applied to removal of unwanted reflections from the borders of the investigation medium

- FK MIGRATION - used to collapse the diffraction hyperboles and arrange the reflectors in their real position.

- CONVERT TO DEPTH - conversion of time profiles to depth. The conversion speed, used in this step, was obtained through the hyperbolic adjustment of some diffracting points found in the investigated area.

The same parameters for gain and filters were applied to every section with the intention of comparing the signal amplitudes. The average speed of propagation of the electromagnetic wave in the soil was determined by the method of hyperbolic adjustment of diffracting points related to pipes found close to the surface (Yilmaz 1987). The adjustment of hyperbolic events shows that the average of the adapted speeds was $0.08 \mathrm{~m} / \mathrm{ns}$. Figure 7 shows the flow diagram of the GPR data processing sequence.

\section{Gpr Results And Discussion}

The analysis of the results of GPR is done through the correlation between the geometry and the amplitude of the reflecting events. In the radar sections, there are distinct reflection patterns that reflect the electrical behavior of the environment when passing through high frequency electromagnetic fields.

The first reflection pattern observed (PR1) has high amplitude, horizontal and inclined reflectors, continuous and discontinuous, and corresponds to the characteristic pattern of landfills and soils (Fig. 8a). This pattern is recorded in all sections on their surfaces, that is, up to an average depth of 2 meters.

The second reflection pattern (PR2) is characterized by low amplitude, chaotic and totally discontinuous reflectors (Fig. 8b), and occurs just below PR1. This reflection pattern marks the region where the GPR electromagnetic signal is absorbed by the medium. This absorption must be the effect of attenuation of the signal by the presence of electrically conductive layers, such as clay, siltstones or sandstones with a clay matrix.

In addition to these two reflection patterns, hyperbolic reflectors related to underground interference (pipes, ducts, electrical wires, etc., Fig. 8c) are noted in the GPR sections.

The GPR section carried out at Simplício Mendes street shows a deformation in the reflection pattern PR1, resulting from the sinking of the land on December 29, 1999 (Fig. 9). This sinking occurs in the GPR section between positions at 135 and 182 meters, with the center at 160 meters. This anomalous zone is evidenced by the inflection of reflectors. 
The GPR section carried out at Francisco Mendes street shows a deformation in the reflection pattern PR1, resulting from the sinking of the land on July 31, 2008 (Fig. 10). This sinking occurs in the GPR section between positions at 34 and 70 meters, with the center at 53 meters. This anomalous zone is evidenced by the inflection of reflectors.

The results of GPR obtained in the areas with buried cavities indicate the presence of discontinuities in the GPR reflectors that can be related to accommodation fractures. With the reflection patterns determined for the settlement areas and for the fractures, there were acquisitions of GPR along the main avenue of the city of Teresina, where there is the highest demographic density of buildings.

The GPR results obtained along some streets in Teresina show reflection patterns similar to those in areas with karst dissolution structures (Doolittle et al. 1998; Anchuela et al. 2014; Ronen et al. 2019). In one of the sections carried out on Paissandu avenue, 3 areas were identified that show typical reflection patterns of land settlement areas (sinkholes; Fig. 11), with the presence of discontinuities in the reflectors that are related to possible vertical fractures. In these fracture zones there is the leaching of fine sediments (clay) and permanence of thicker sediments, which causes an increase in the amplitude of the reflectors inside the collapse zones.

\section{Conclusions}

GPR investigations carried out on the streets and avenues of Teresina / PI show pedological coverage and / or landfill up to a maximum depth of 3 meters and hyperbolic targets related to underground interference (ducts, plumbing, pipes, etc.).

In places where there is a record of subsidence (Simplício Mendes and Francisco Mendes streets), the GPR reflectors are tilted, that is, they stop being horizontal and lean towards the center of the subsidence. At the ends of these areas, there is also the interruption of the reflectors, suggesting the rupture of the geological layers. This pattern is typical of cave undermining.

The results of GPR obtained on the main avenue of the city, where there is a high concentration of buildings and a higher occurrence of sinkholes, show high amplitude anomalies associated with reflector discontinuities. Thus, GPR proved to be an important tool in locating possible areas of land collapse in the Teresina region, demonstrating an important use of this method as an early warning for sinkholes in similar areas.

The interpretation of aeromagnetometric data and aerial images (SRTM) showed that the occurrence of sinkholes was associated with geological lineaments principally in the NW-SE direction, and enhanced the understanding of the structural framework of the study area.

\section{Declarations}




\section{ACKNOWLEDGMENTS}

The authors would like to thank the Geological Survey of Brazil/CPRM for financing the Project and the Institute of Geosciences at the University of Brasília for the assignment of GPR equipment.

\section{Declaration of interests}

The authors declare that they have no known competing financial interests or personal relationships that could have appeared to influence the work reported in this paper.

\section{References}

1. Anchuela ÓP, Casas-Sainz AM, Soriano MA, Pocoví-Juan A (2009) Mapping subsurface karst features with GPR: results and limitations. Environ Geol, 58:391-399. https://doi:10.1007/s00254008-1603-7

2. Anchuela ÓP, Casas-Sainz AM, Pocoví-Juan A, Garbí HG, Calvín P (2014) Characterization of the Karstic Process in an Urban Environment Using GPR Surveys. Journal of Materials in Civil Engineering, 26(8), 05014004-. https://doi:10.1061/(asce)mt.1943-5533.0001072

3. Annan AP (2002) GPR - History, Trends, and Future Developments. Subsurface Sensing Technologies and Applications. Vol. 3(4): 253-270. https://doi.org/10.1023/A:1020657129590

4. Aquino $A E B$ de (2020) Contribuição à cartografia geotécnica no município de Teresina-PI: cartas de suscetibilidade à ocorrência de solos problemáticos e prática de fundação com uso de geoprocessamento. Dissertation, UFPE, 198p. https://repositorio.ufpe.br/handle/123456789/38375

5. Argentieri A, Carluccio R, Cecchini F, Chiappini M, Ciotoli G, De Ritis R, Di Filippo M, Di Nezza M, Marchetti M, Margottini S, Materni V, Meloni F, Nardi A, Rotella G, Sapia V, Venuti A (2015) Early-stage sinkhole formation in the Acque Albule basin of central Italy from geophysical and geochemical observations. Engineering Geology, 191:36-47. https://doi:10.1016/j.enggeo.2015.03.010

6. Arifin MH, Kayode JS, Izwan MK, Zaid HAH, Hussin H (2019) Data for the potential gold mineralization mapping with the applications of Electrical Resistivity Imaging and Induced Polarization geophysical surveys. Data in Brief, 22, 830-835. https://doi:10.1016/j.dib.2018.12.086

7. Boyd D (1967) The contribution of airborne magnetic surveys to geological mapping. In: MORLEY, L. A. (Ed.). Mining and Groundwater Geophysics. Otawa: Geological Survey of Canada, 1967. p. 2013227. (Economic Geology Report, 26)

8. Bradford JH (2007) Frequency-dependent attenuation analysis of ground-penetrating radar data. GEOPHYSICS, 72(3), J7-J16. https://doi:10.1190/1.2710183

9. Casas A, Pinto V, Rivero L (2000) Fundamental of ground penetrating radar in environmental and engineering applications. Ann. Geophys. 43 (6). https://doi.org/10.4401/ag-3689 
10. Castro DL de, Bezerra FM, Fuck RA, Vidotti RM (2016) Geophysical evidence of pre-sag rifting and post-rifting fault reactivation in the Parnaíba basin, Brazil. Solid Earth, 7, 529-

548. https://doi.org/10.5194/se-7-529-2016

11. Consórcio ENCAL/LASA/PROSPEC (1989) Projeto Aeromagnetométrico Bacia do Maranhão - Bloco Oeste. Relatório Final de Aquisição e Processamento de Dados, 4 vol., texto e anexos, Petróleo Brasileiro S.A., PETROBRAS, DEPEX, Rio de Janeiro

12. Chalikakis K, Plagnes V, Guerin R, Valois R, \& Bosch FP (2011) Contribution of geophysical methods to karst-system exploration: an overview. Hydrogeology Journal, 19(6), 11691180. https://doi:10.1007/s10040-011-0746-x

13. Chambers JE, Kuras O, Meldrum PI, Ogilvy RD, Hollands J (2006) Electrical resistivity tomography applied to geologic, hydrogeologic, and engineering investigations at a former waste-disposal site. GEOPHYSICS, 71(6), B231-B239. https://doi:10.1190/1.2360184

14. De Lima OAL, Sato HK, Porsani MJ (1995) Imaging industrial contaminant plumes with resistivity techniques. Journal of Applied Geophysics, 34(2): 93-108. https://doi:10.1016/09269851(95)00014-3

15. Dourado JC, Malagutti Filho W, Braga AC, Nava N (2001) Detection of cavities in sandstone using gravity, resistivity and GPR methods. RBGF, 19(1): 19-32. https://doi.org/10.1590/S0102261X2001000100002

16. Doolittle JA, Collins ME (1998) A comparison of EM induction and GPR methods in areas of karst. Geoderma, 85(1), 83-102. https://doi:10.1016/s0016-7061(98)00012-3

17. Ezersky M (2008) Geoelectric structure of the Ein Gedi sinkhole occurrence site at the Dead Sea shore in Israel. Journal of Applied Geophysics, 64(3-4), 56-69

18. Ezersky M, Bruner I, Keydar S, Trachtman P, Rybakov M (2006) Integrated study of the sinkhole development site on the western shores of the Dead Sea using geophysical methods: Near Surface Geophysics, Vol. 4, pp. 335-343

19. Façanha AC (1988) A evolução urbana de Teresina: agentes, processos e formas espaciais da cidade. Dissertation, Universidade Federal de Pernambuco, UFPE

20. Façanha AC (2003) A evolução urbana de Teresina: passado, presente e ... Carata CEPRO, Teresina, v. 22 , n. 1 , p. $59-69$

21. Frumkin A (2013) New Developments of Karst Geomorphology Concepts. In: Shroder, J. (Ed. in Chief), Frumkin, A. (Ed.), Treatise on Geomorphology. Academic Press, San Diego, CA, vol. 6, Karst Geomorphology, 1-13

22. Gutiérrez F (2010) Hazards associated with karst. In Alcántara-Ayala, I. and Goudie, A. (Editors), Geomorphological Hazards and Disaster Prevention: Cambridge University Press, Cambridge, pp. 161-173

23. Gutiérrez F, Mozafari M, Carbonel D, Gómez R, Raeisi E (2015) Leakage problems in dams built on evaporites. The case of La Loteta Dam (NE Spain), a reservoir in a large karstic depression generated 
by interstratal salt dissolution. Engineering Geology, 185, 139-

154. https://doi:10.1016/j.enggeo.2014.12.009

24. Hoover RA (2003) Geophysical Choices for Karst Investigations. Sinkholes and the Engineering and Environmental Impacts of Karst. https://doi.org/10.1061/40698(2003)48

25. Hussain Y, Uagoda R, Borges WR, Nunes J, Hamza O, Condori C, Aslam K, Dou J, Cárdenas-Soto M (2020) The potential use of methods to identify cavities, sinkholes and pathways for water infiltration: a case study from Mambaí, Brazil. Online in https://doi.org/10.1002/essoar.10503456.1

26. Kruse $S$, Grasmueck $M$, Weiss $M$, Viggiano $D$ (2006) Sinkhole structure imaging in covered Karst terrain. Geophysical Research Letters, 33(16). https://doi:10.1029/2006gl026975

27. Lago AL, Elis VR, Giacheti HL (2006) Aplicação integrada de métodos geofísicos em uma área de disposição de resíduos sólidos urbanos em Bauru-SP. Revista Brasileira de Geofísica, 24(3). https://doi:10.1590/s0102-261×2006000300005

28. Lago AL, Elis VR, Borges WR, Penner GC (2008) Geophysical investigation using resistivity and GPR methods: a case study of a lubricant oil waste disposal area in the city of Ribeirão Preto, São Paulo, Brazil. Environmental Geology, 58(2), 407-417. https://doi:10.1007/s00254-008-1511-x

29. Lelièvre PG, Oldenburg DW, Williams NC (2009) Integrating geological and geophysical data through advanced constrained inversions. Exploration Geophysics, 40(4), 334. https://doi:10.1071/eg09012

30. Martini JEJ (2000) Dissolution of quartz and silicate minerals. In: Klimchouk, A. B.; Ford, D. C.; Palmer, A. N.; Dreybrodt, W. (Ed.). Speleogenesis: Evolution of Karst Aquifers. Huntsville/USA: National Speleological Society, p.171-174

31. Martinez-Lopez J, Rey J, Duenas J, Hidalgo C, Benavente J (2013) Electrical tomography applied to the detection of subsurface cavities. Journal of Cave and Karst Studies, 75(1): 2837. https://doi:10.4311/2011ES0242

32. Mekkawi MM, Fergani ESA, Abdella KA (2017) Seismic Risk Zones and Faults Characterization using Geophysical Data. Journal of Geology \& Geophysics, 6:311. https://doi:10.4172/23818719.1000311

33. McMechan GA, Loucks RG, Zeng X, Mescher P (1998) Ground penetrating radar imaging of a collapsed paleocave system in the Ellenburger dolomite, central Texas. Journal of Applied Geophysics, 39(1), 1-10. https://doi:10.1016/s0926-9851(98)00004-4

34. Milanovic PT (2000) Geological engineering in karst: Zebra, Belgrade, $347 \mathrm{p}$

35. Michot D, Benderitter Y, Dorigny A, Nicoullaud B, King D, Tabbagh A (2003) Spatial and temporal monitoring of soil water content with an irrigated corn crop cover using surface electrical resistivity tomography. Water Resources Research, 39(5). https://doi:10.1029/2002wr001581

36. Nouioua I, Rouabhi A, Fehdi C et al (2012) The application of GPR and electrical resistivity tomography as useful tools in detection of sinkholes in the Cheria Basin (northeast of Algeria). Environmental Earth Sciences68, 1661-1672. https://doi.org/10.1007/s12665-012-1859-9

37. Pazzi V, Di Filippo M, Di Nezza M, Carlà T, Bardi F, Marini F, Fontanelli K, Intrieri E, Fanti R (2018) Integrated geophysical survey in a sinkhole-prone area: Microgravity, electrical resistivity 
tomographies, and seismic noise measurements to delimit its extension. Engineering Geology, 243, 282-293. https://doi:10.1016/j.enggeo.2018.07.016

38. Pimentel J (2008) Contribuição para o Entendimento dos processos de Colapso e Subsidência de solo em Teresina. CPRM - Serviço Geológico do Brasil - DEGET/DHT

39. Revil A, Karaoulis M, Johnson T, Kemna A (2012) Review: Some low-frequency electrical methods for subsurface characterization and monitoring in hydrogeology. Hydrogeology Journal, 20(4), 617658. https://doi:10.1007/s10040-011-0819-x

40. Rodriguez V, Gutiérrez F, Green AG, Carbonel D, Horstmeyer H, Schmelzbach C (2014) Characterizing Sagging and Collapse Sinkholes in a Mantled Karst by Means of Ground Penetrating Radar (GPR). Environmental \& Engineering Geoscience, 20(2), 109-132. https://doi:10.2113/gseegeosci.20.2.109

41. Ronen A, Ezersky M, Beck A, Gatenio B, Simhayov RB (2018) Use of GPR method for prediction of sinkholes formation along the Dead Sea Shores, Israel.

Geomorphology. https://doi:10.1016/j.geomorph.2018.11.030

42. Rucker DF, Noonan GE, Greenwood WJ (2011) Electrical resistivity in support of geological mapping along the Panama Canal. Engineering Geology, 117(1-2), 121-

133. https://doi:10.1016/j.enggeo.2010.10.012

43. Sandmeier KJ (2012) REFLEXW Version 7.0 for Windows 9x/2000/NT/XP. Program for the processing of seismic, acoustic or electromagnetic reflection, refraction and transmission data. Manual do Software, 192p

44. Sevil J, Gutiérrez F, Zarroca M, Desir G, Carbonel D, Guerrero J, Linares R, Roque C, Fabregat I (2017) Sinkhole investigation in an urban area by trenching in combination with GPR, ERT and highprecision leveling. Mantled evaporite karst of Zaragoza city, NE Spain. Engineering Geology, 231, 920. https://doi:10.1016/j.enggeo.2017.10.009

45. Smith DL (1986) Application of the pole-dipole resistivity technique to the detection of solution cavities beneath highways. Geophysics, 51(3), 833-837. https://doi:10.1190/1.1442135

46. Thierry P, Debeblia N, Bitri A (2005) Geophysical and geological characterization of karst hazards in urban environments: application to Orléans (France). Bulletin of Engineering Geology and the Environment, 64(2), 139-150. https://doi:10.1007/s10064-004-0247-4

47. Vestena LR, Kobiyama M, Santos LJC (2002) Considerações Sobre Gestão Ambiental em Áreas Carste. RA' EGA (UFPR), V. 4(6): 81-94. http://dx.doi.org/10.5380/raega.v6i0.18518

48. Waltham T, Bell F, Culshaw M (2005) Sinkholes and Subsidence. Springer, Chichester (382 pp)

49. Yilmaz O (1987) Seismic Data Processing: Society of Exploration Geophysicists - Investigations in Geophysics, V.2, p. 526

50. Zisman ED, Wightman MJ, Taylor C (2005) The Effectiveness of GPR in Sinkhole Investigations. Sinkholes and the Engineering and Environmental Impacts of Karst. https://doi:10.1061/40796(177)65

\section{Figures}




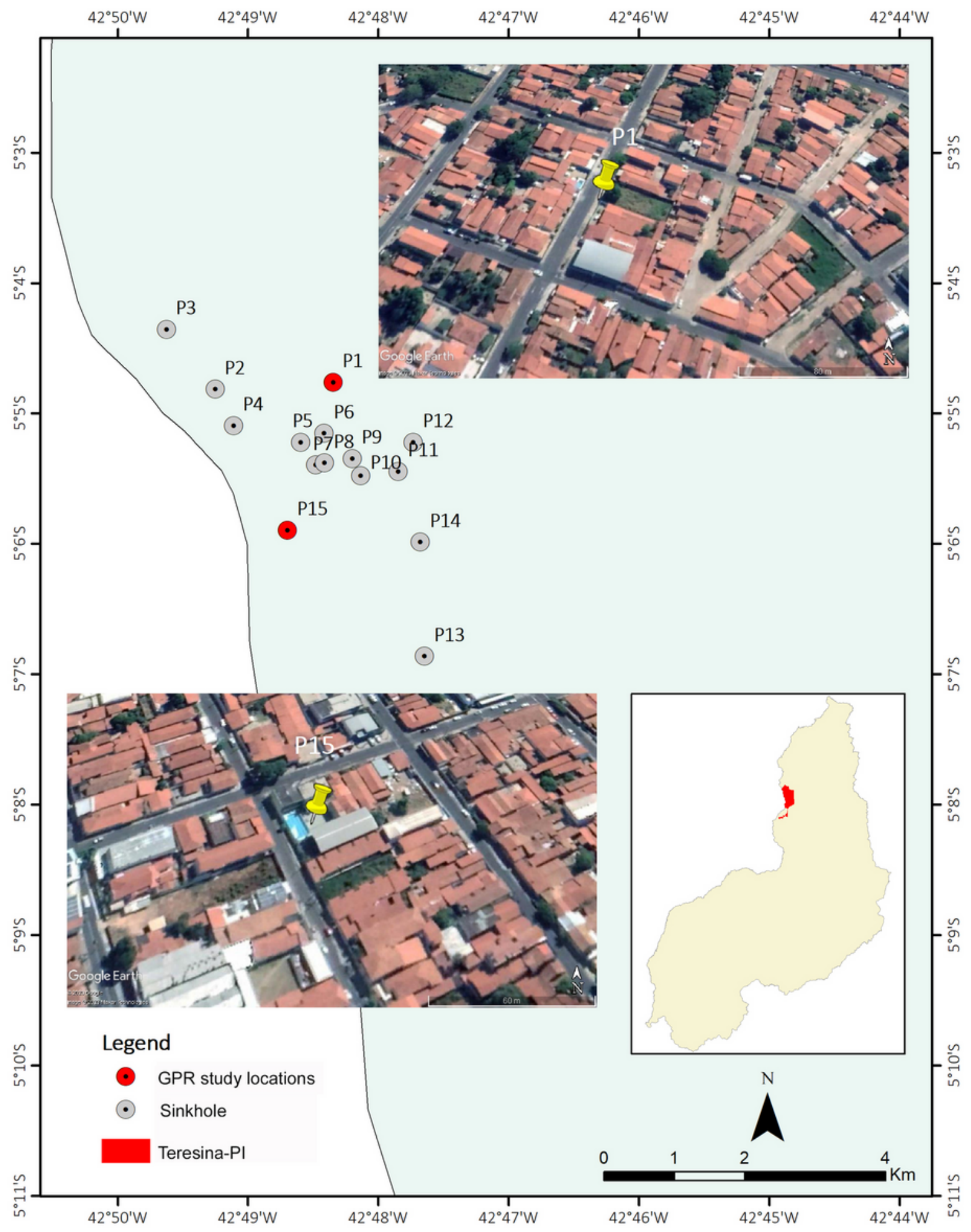

\section{Figure 1}

Location map of the city of Teresina in Piauí State, highlighting the occurrence of sinkholes in the central area of the city, as well as the GPR study locations 
(a)

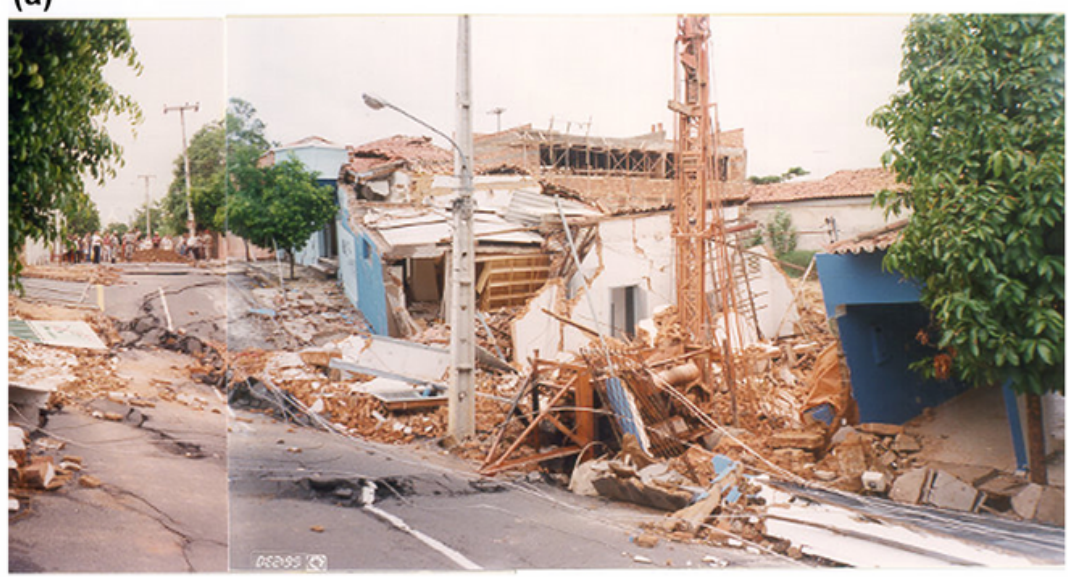

(b)

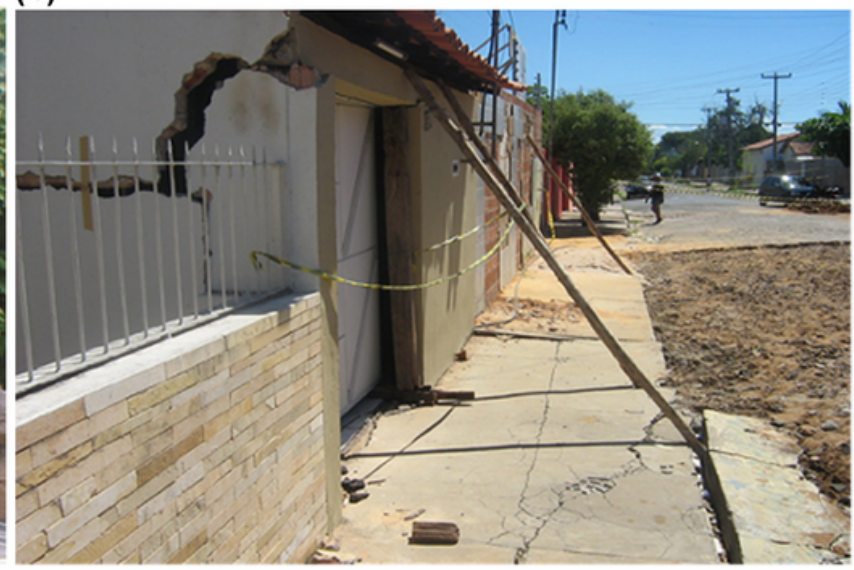

Figure 2

a Photo shows the collapse of the terrain caused by percussive drilling on Simplício Mendes street, in 1999. b Photo shows the collapse that occurred on Francisco Mendes street, in 2008 (Pimentel, 2008)
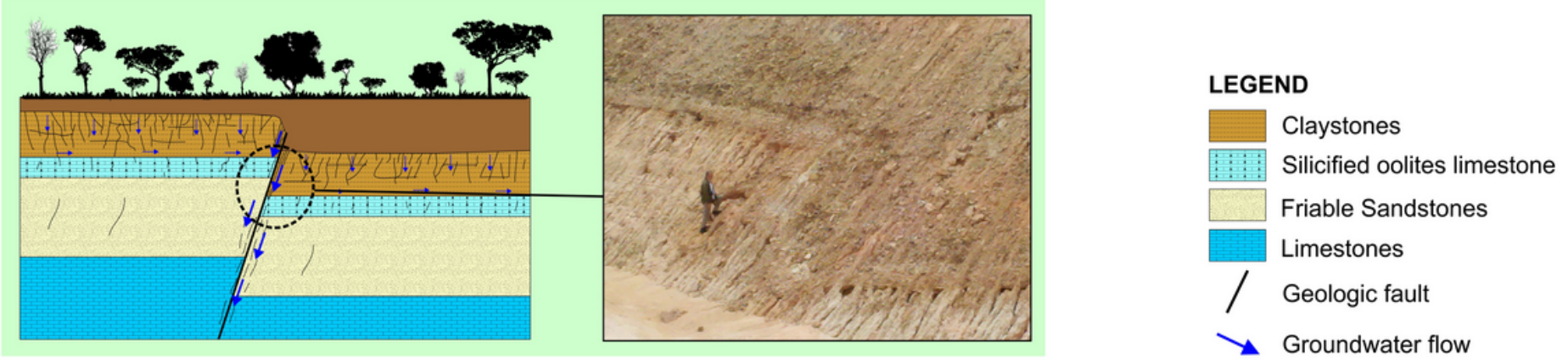

The high flow of groundwater in the fault zone intensifies the dissolution of the sandstone
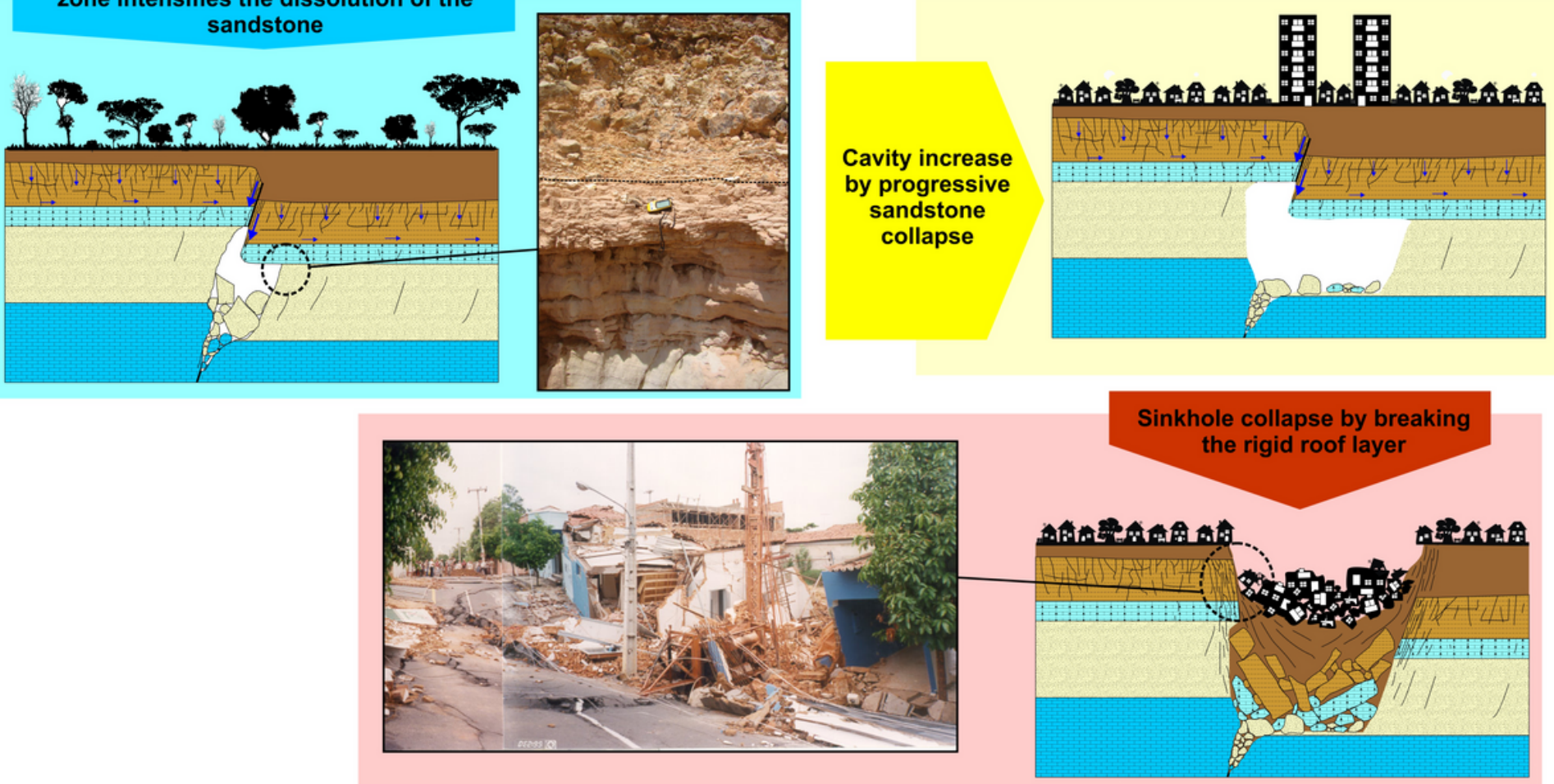

Figure 3 
Geological model proposed for the city of Teresina-PI, which has a history of sinkholes in the central region of the urban area

a)

$42^{\circ} 50^{\prime} \mathrm{W} \quad 42^{\circ} 45^{\prime} \mathrm{W} \quad 42^{\circ} 40^{\prime} \mathrm{W}$

b)

$42^{\circ} 50^{\prime} \mathrm{W}$

\section{Figure 4}

Magnetic lineaments interpreted from aeromagnetometric images. a Anomalous Magnetic Field. b Anomalous Magnetic Field Reduced to the Pole. c First Vertical Derivative of the Anomalous Magnetic Field. d First Vertical Derivative of the Anomalous Magnetic Field Reduced to the Pole 


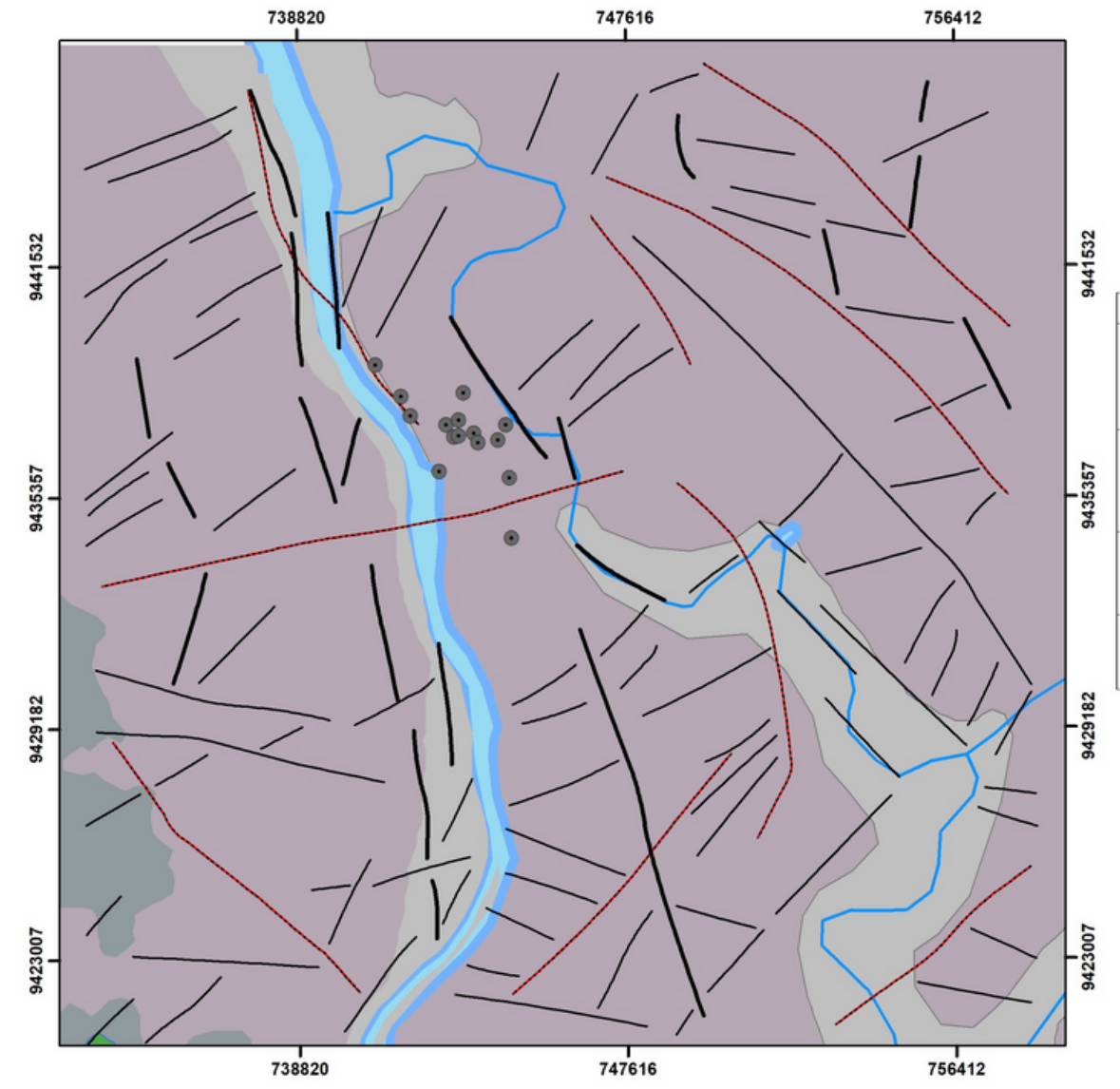

\section{Legend}

- Sinkholes

.. Magnetic Lineament

Lineament

- Hidrography

Parnaiba Province

Mearim Group

Corda Formation: sandstones, clay and shales. Environment

desert, fluvial and lake sandstones, clay and shales. Environment desert, fluvial and lake

Balsas Group

$\mathrm{Tm}$ Motuca Formation: redish sanstones, with limestone and

Tm anhydrite lenses. Desert environment with associated lakes

Pedra de Fogo Formations: sandstones, shales, limstones and

P12p silexites. Shallow and coastal marine environments.

C1po Piaui Formation: sandstones, siltstones, shales and limestones. Continental fluvial and coastal environments with marine intercalations.

鎬
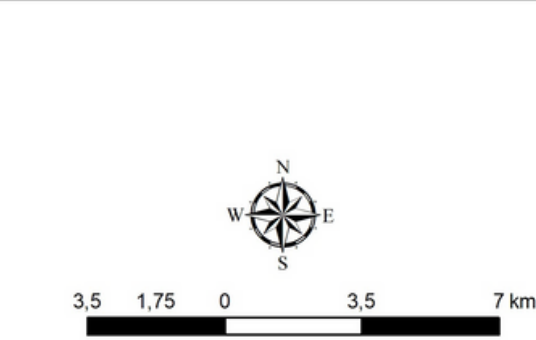

COORDNATE SYSTEM: ZONE UTM 23 S DATUM:SIRGAS2000 DATA BASE: CPRM

\section{Figure 5}

Geological map of the city of Teresina with the location of the main geological and magnetic lineaments, and sinkholes records 

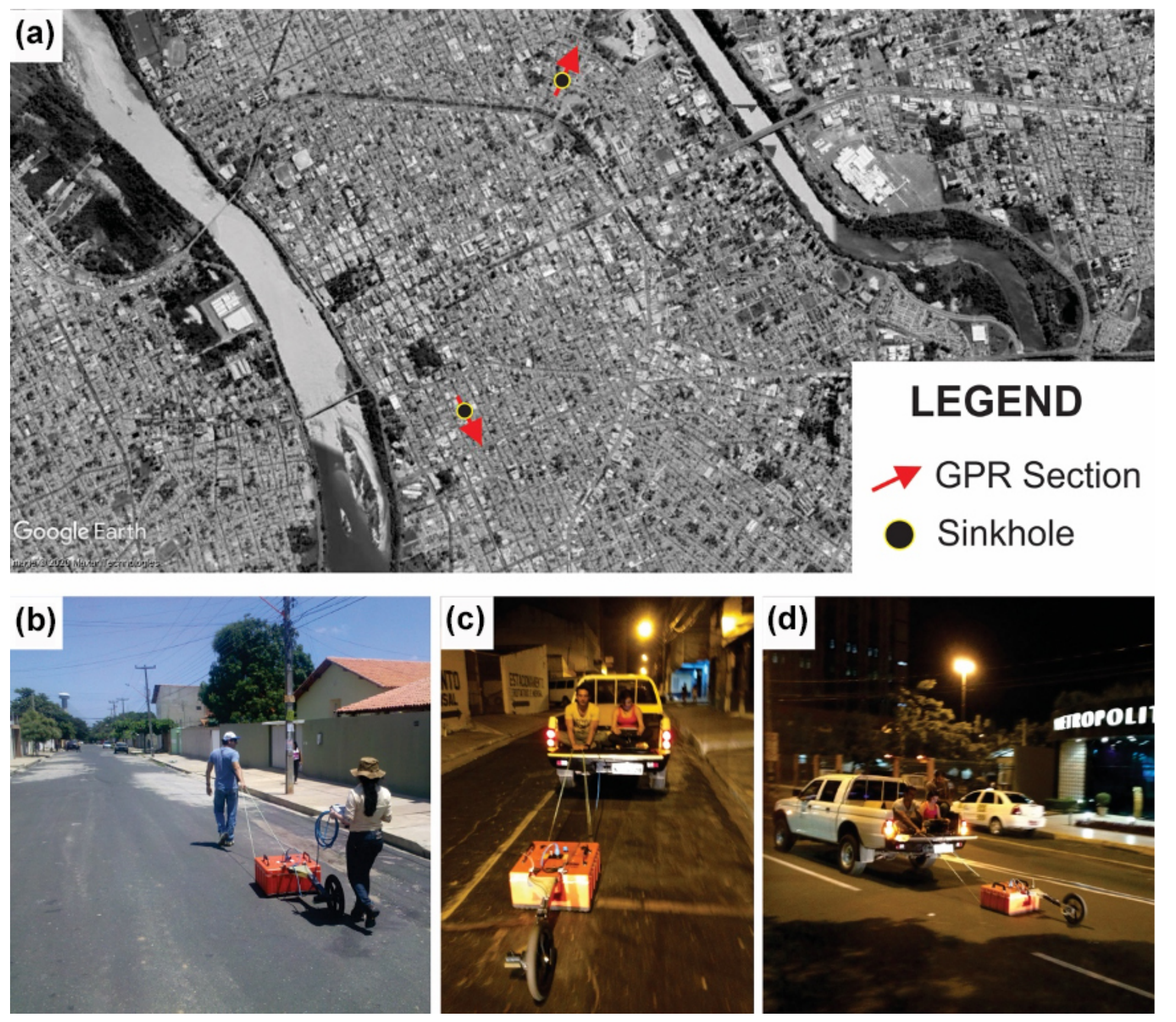

\section{Figure 6}

a Locations of the GPR sections in Teresina-PI. b, $c$ and $d$ Photos show the acquisition of GPR data on the streets of Teresina, PI 


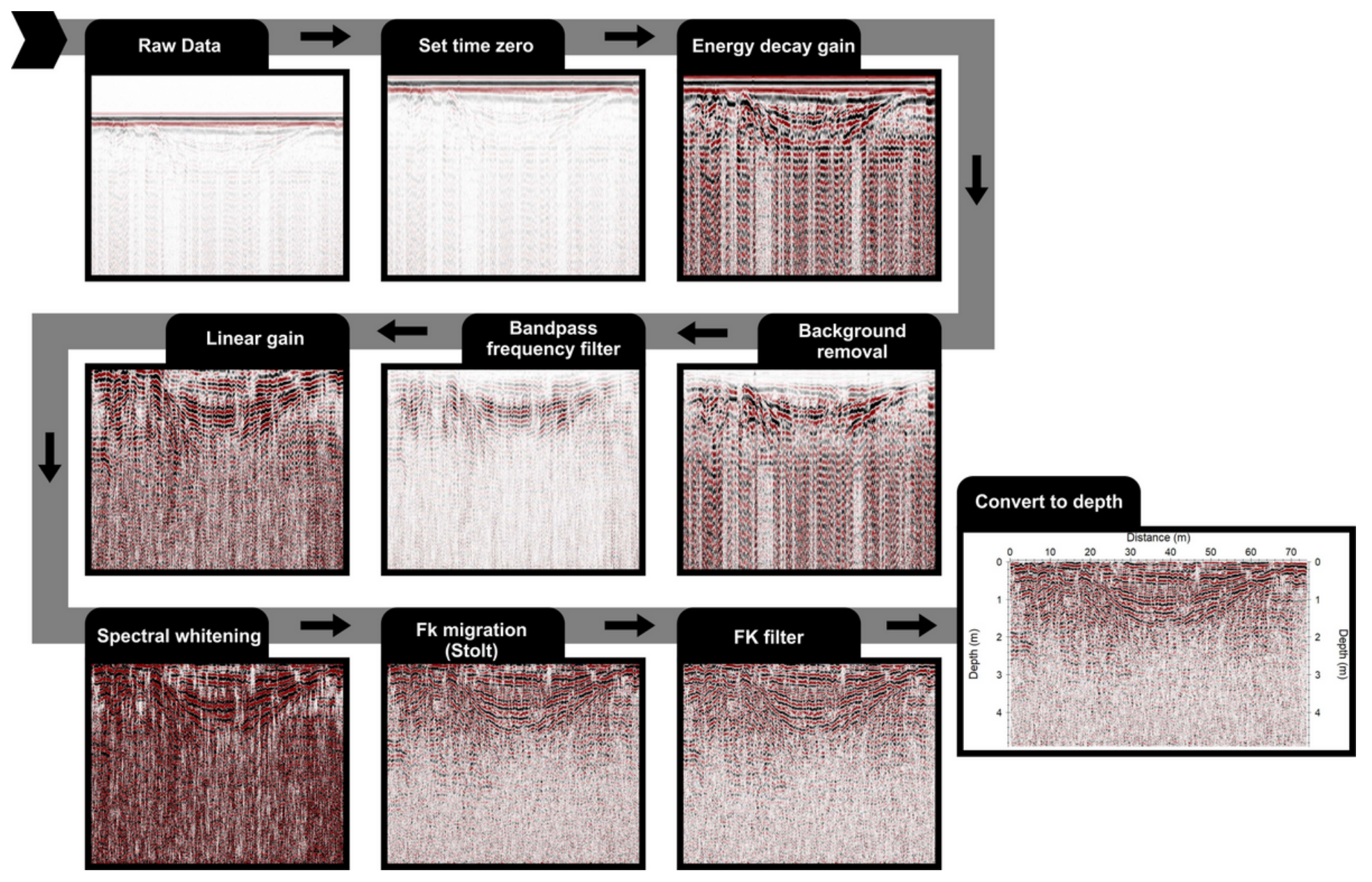

Figure 7

Flow diagram of the GPR data processing sequence 

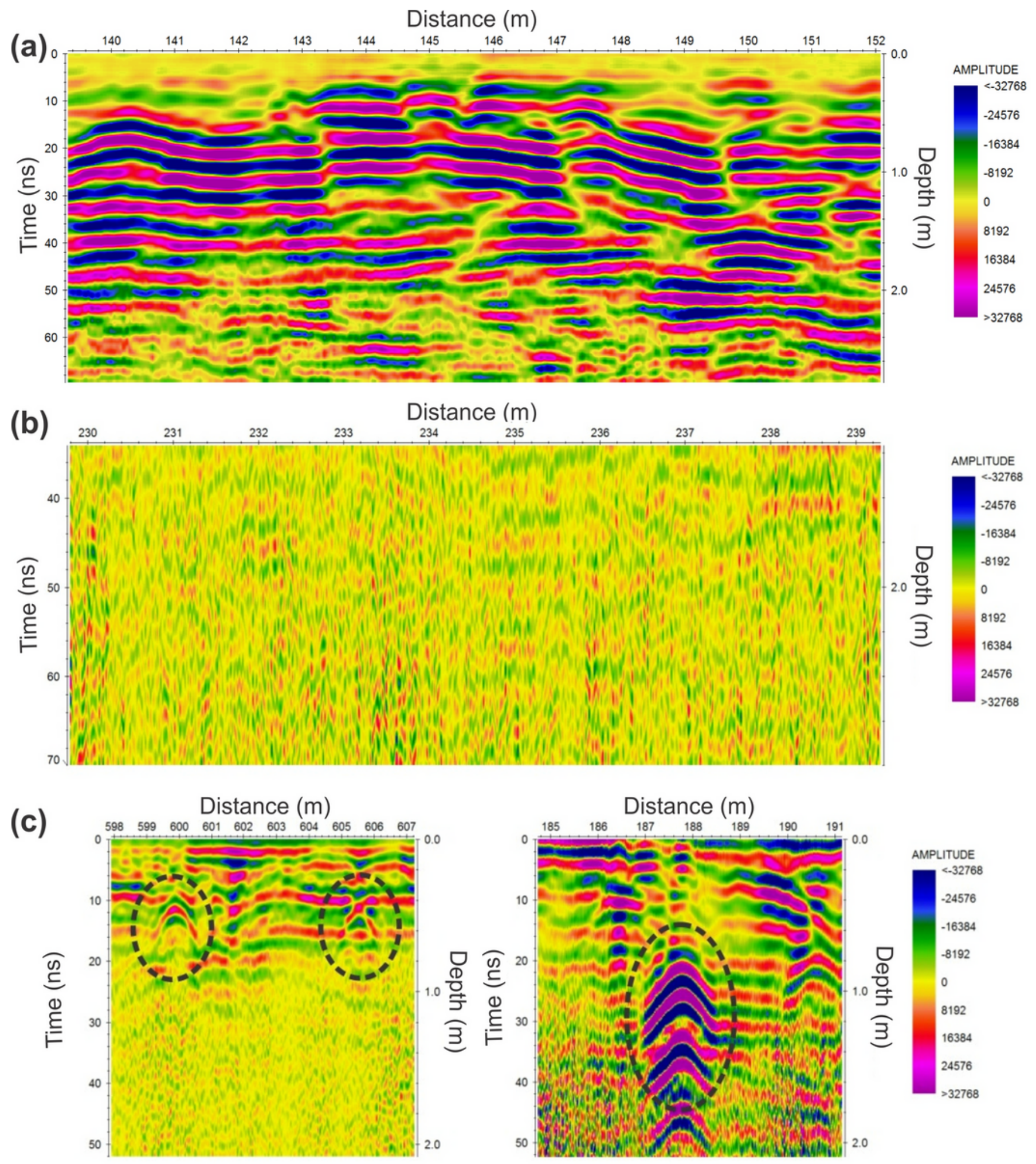

Figure 8

Details of GPR sections carried out in the urban area of Teresina / PI, where the reflection patterns (PR1) related to soils and landfills are evident (8a); the standard (PR2) related to the GPR signal attenuation area (conductive zone, $8 \mathrm{~b}$ ); and the hyperbolic reflectors related to underground interference (pipes, ducts, etc., 8c). 

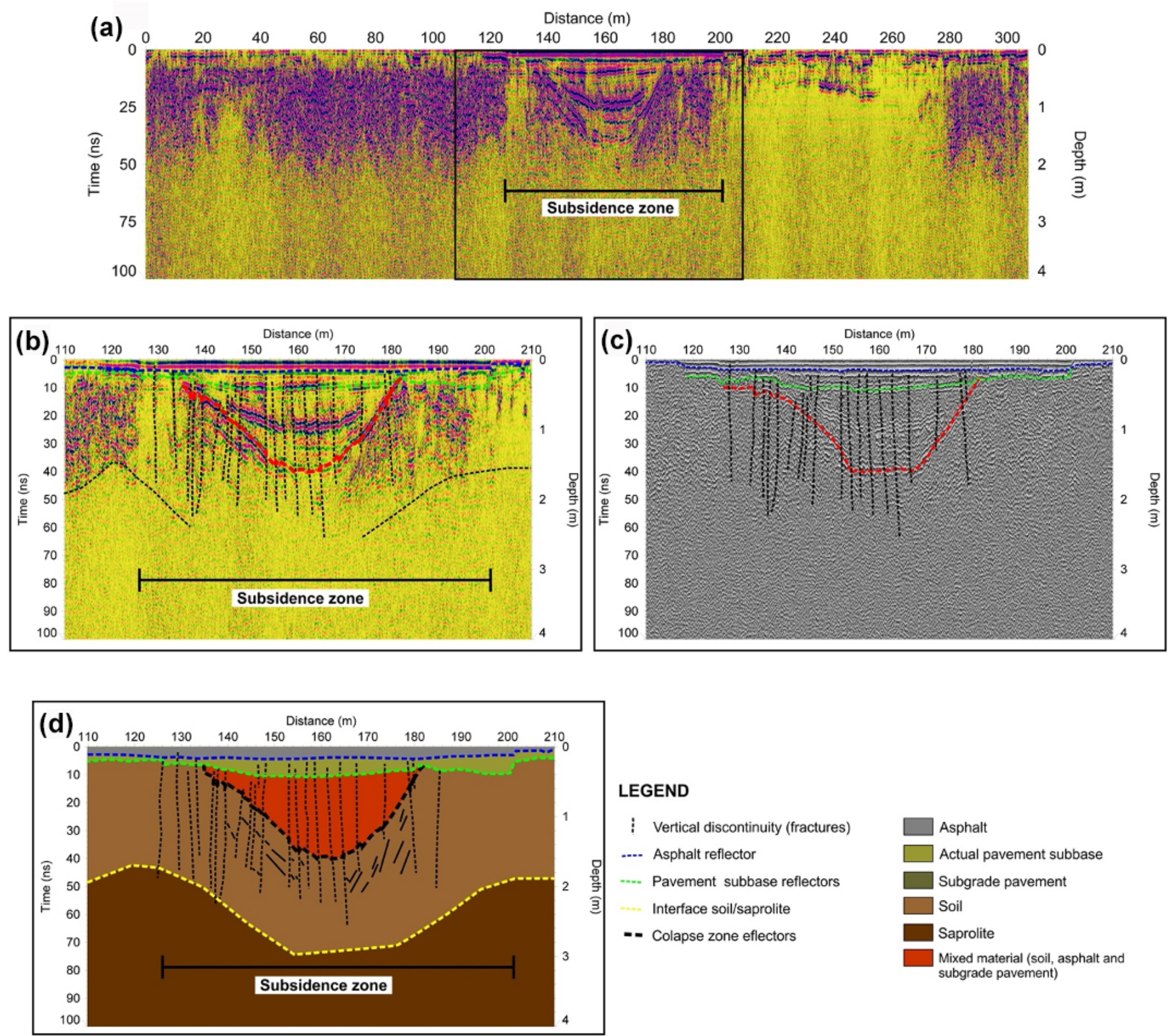

\section{LEGEND}

Vertical discontinuity (fractures)

Asphalt

..-. Asphalt reflector

-.. Pavement subbase reflectors

Interface soil/saprolite

-- Colapse zone eflectors

Actual pavement subbase

Subgrade pavement

Soil

Saprolite

Mixed material (soil, asphalt and subgrade pavement)

Figure 9

GPR section carried out at Simplício Mendes street, Teresina / PI. a Detail of the section showing the typical reflection pattern of areas where subsidence occurred. b Same section interpreted. c Instantaneous frequency section with interpretation. d Geological model obtained with GPR data 

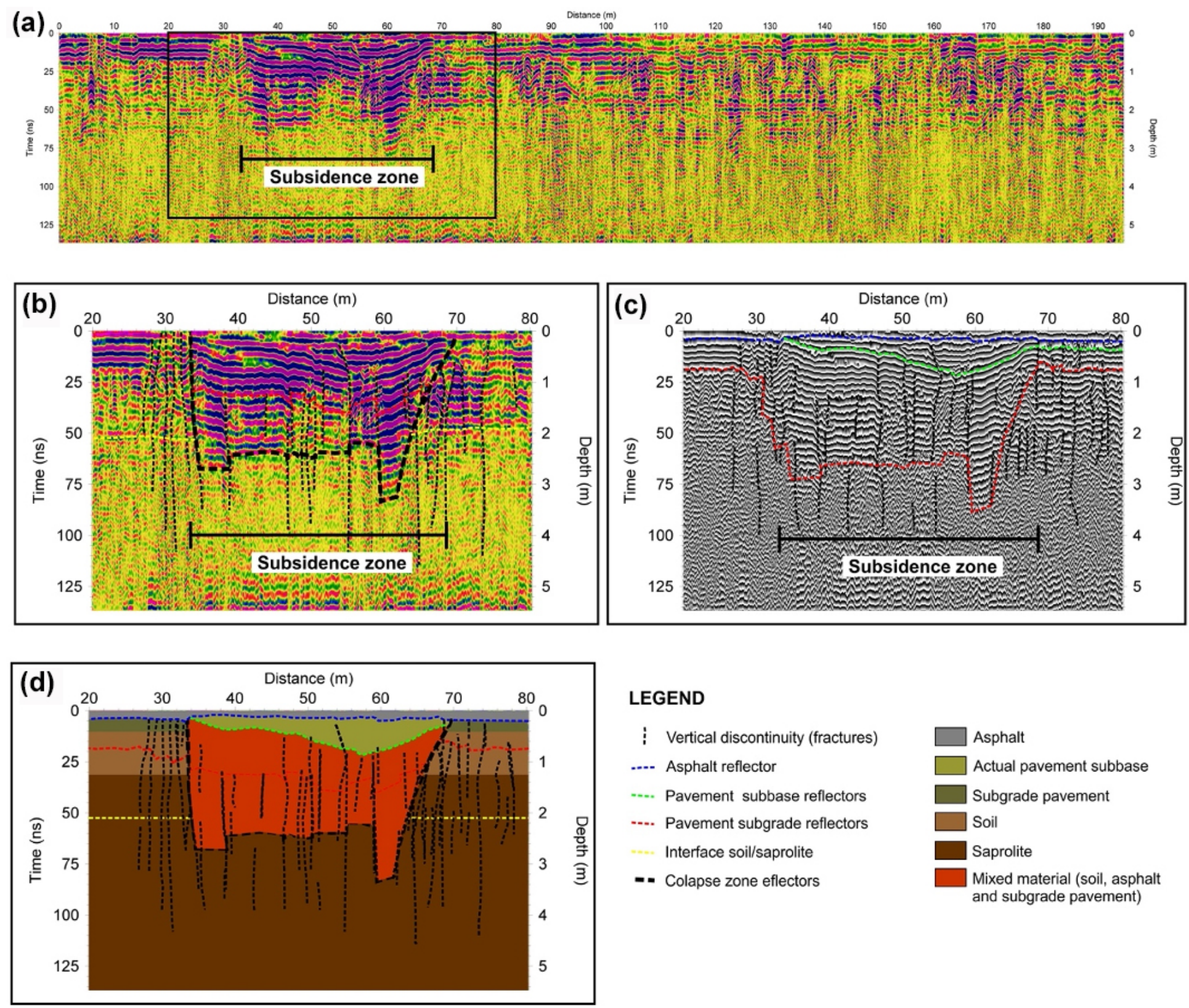

\section{LEGEND}

i Vertical discontinuity (fractures)

..-. Asphalt reflector

-... Pavement subbase reflectors

-... Pavement subgrade reflectors

-... Interface soil/saprolite

-. Colapse zone eflectors $\square$ Asphalt

Actual pavement subbase

Subgrade pavement

Soil

Saprolite

Mixed material (soil, asphalt and subgrade pavement)

\section{Figure 10}

GPR section carried out at Francisco Mendes street, Teresina / PI. a Detail of the section showing the typical reflection pattern of areas where subsidence occurred. b Same section interpreted. c Instantaneous frequency section with interpretation. $d$ Geological model obtained with GPR data 


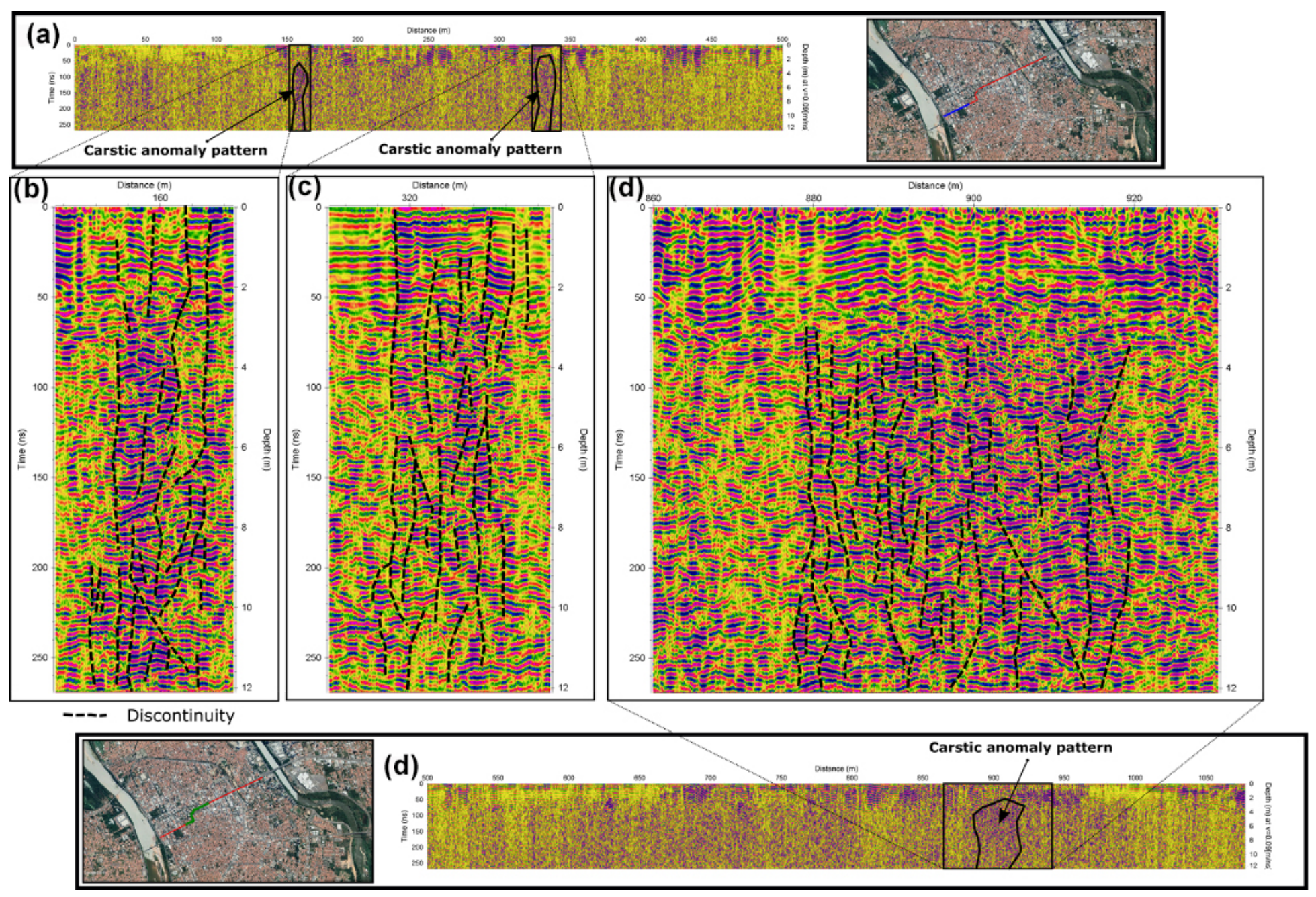

Figure 11

GPR section acquired in Paissandu avenue, Teresina, PI. a Initial part of the GPR section and satellite image with its location. Reflection anomalies related to land settlement areas (sinkholes): Anomalies GPR patterns in position (b) 150 to 170 meters, (c) 310 to 336 meters, and (d) 860 to 930 meters. d Middle part of the GPR section and satellite image with its location. 